Check for updates

Cite this: J. Mater. Chem. C, 2021, 9, 5486

Received 4th November 2020, Accepted 1st April 2021

DOI: $10.1039 / \mathrm{d} 0 \mathrm{tc} 05210 \mathrm{~h}$

rsc.li/materials-c

\section{Multianvil high-pressure/high-temperature synthesis and characterization of magnetoelectric $\mathrm{HP}-\mathrm{CO}_{3} \mathrm{TeO}_{6}^{\dagger}$}

\author{
Elisabeth Selb, ${ }^{a}$ Toni Buttlar, ${ }^{b}$ Oliver Janka, (D) Martina Tribus, ${ }^{d}$ \\ Stefan G. Ebbinghaus (D) $^{\mathrm{b}}$ and Gunter Heymann (D) *a
}

\begin{abstract}
By high-pressure/high-temperature multianvil synthesis a new high-pressure (HP) phase of $\mathrm{CO}_{3} \mathrm{TeO}_{6}$ was obtained. The compound crystallizes in the acentric trigonal crystal system of the $\mathrm{Ni}_{3} \mathrm{TeO}_{6}$-type structure with space group $R 3$ and the following unit cell parameters and refinement results: $a=$ 519.37(6) pm, $c=1382.4(2) \mathrm{pm}, V=322.93 \AA^{3}, R_{1}=0.0150, w R_{2}=0.0374$, GooF $=1.114$ and a Flack parameter of $0.04(5)$. High-temperature powder X-ray diffraction (PXRD) measurements showed an exceptionally high-temperature stability of the HP-modification up to $1070 \mathrm{~K}$. Magnetic measurements revealed an antiferromagnetic ordering below $T_{\mathrm{N}}=58.2(1) \mathrm{K}$ and a spin-flop-type transition at $T=3 \mathrm{~K}$ with a critical magnetic field of $H_{\text {crit }}=10.8(1) \mathrm{kOe}$. Magnetic and magnetoelectric (ME) transition temperatures were determined by specific heat measurements and exhibited a non-hysteretic behavior of the magnetoelectric coupling. Additionally, from the UV-Vis reflectance spectra a direct and an indirect band gap of $E_{\mathrm{g}}=1.88 \mathrm{eV}$

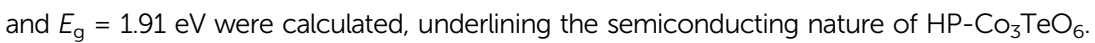

\section{Introduction}

In recent years, research on magnetoelectric (ME) compounds has attracted enormous attention in materials science and condensed matter physics. Without magnetic and magnetoelectric materials many forms of current technology in particular microelectronics would be unimaginable. To further enhance the performance of the corresponding devices, new technologies are required. For example, materials that combine ferroelectricity and ferromagnetism allow fast and energy efficient electric writing of a magnetic information. Therefore, there is great demand for multiferroics, where these two phenomena are intimately coupled. $^{1-3}$

In this regard, novel metal tellurates $\mathrm{M}_{3} \mathrm{TeO}_{6}(\mathrm{M}=\mathrm{Ni}$, Co, $\mathrm{Mn}, \mathrm{Cu}$ ) have gained great importance. These materials are

\footnotetext{
${ }^{a}$ Institut für Allgemeine, Anorganische und Theoretische Chemie, Leopold-Franzens-Universität Innsbruck, Innrain 80-82, A-6020 Innsbruck, Austria. E-mail: Gunter.Heymann@uibk.ac.at; Fax:+43-0-512-507 57003

${ }^{b}$ Institut für Chemie, Martin-Luther-Universität Halle-Wittenberg, Kurt-Mothes-Str. 2, D-06120 Halle (Saale), Germany

${ }^{c}$ Anorganische Festkörperchemie, Universität des Saarlandes, Campus C4 1, D-66123 Saarbrücken, Germany

${ }^{d}$ Institut für Mineralogie und Petrographie, Leopold-Franzens-Universität Innsbruck, Innrain 52, A-6020 Innsbruck, Austria

$\dagger$ Electronic supplementary information (ESI) available. CCDC 2032321. For ESI and crystallographic data in CIF or other electronic format see DOI: 10.1039/ dotc05210h
}

classified as type-II multiferroics and show antiferromagnetic ordering at low temperatures. ${ }^{4}$ Remarkably, the ME effect is stronger in type-II multiferroics, because the order parameters are closely linked and not decoupled as in type-I multiferroics. ${ }^{5,6}$ Despite their same stoichiometry (transition metal to tellurium ratio of $3: 1)$ the tellurates $\mathrm{M}_{3} \mathrm{TeO}_{6}(\mathrm{M}=\mathrm{Ni}$, $\mathrm{Co}, \mathrm{Mn}, \mathrm{Cu})$ exhibit different crystal structure-types and different magnetic structures. ${ }^{4} \mathrm{~A}$ brief overview is given in the following.

The longest known tellurate of this composition is $\mathrm{Ni}_{3} \mathrm{TeO}_{6}$. Its crystal structure was already investigated in the year $1967 .{ }^{7}$ Current research on this compound revealed spin driven pyroelectricity $^{8}$ and a so-called colossal magnetoelectric effect (CME) below the antiferromagnetic (AFM) ordering temperature of $T_{\mathrm{N}}=52 \mathrm{~K}^{9-11}$ Exceptional about $\mathrm{Ni}_{3} \mathrm{TeO}_{6}$ is the possibility of a magnetoelectric switching without hysteresis. Thus already small changes in electric and magnetic fields are sufficient for a spin-flop transition. ${ }^{11}$

Hostachy and Coing-Boyat et al. ${ }^{12}$ reported on cubic (Ia $\left.\overline{3}\right)$ $\mathrm{Cu}_{3} \mathrm{TeO}_{6}$, also a type-II multiferroic tellurate, which adopts a bixbyite-type structure and orders in a "three-dimensional spin web" with hexagonal arrangements of the magnetic moments. ${ }^{13}$ One decade later $\mathrm{Mn}_{3} \mathrm{TeO}_{6}$ was discovered, crystallizing in the rhombohedral $\mathrm{Mg}_{3} \mathrm{TeO}_{6}$-type structure. ${ }^{14,15}$ Here, the multiferroic ordering arises from two coexistent incommensurate spin structures with a cycloidal and a helical ordering. ${ }^{16}$ Recently Attfield et al. reported on a magnetically 
frustrated high-pressure $\mathrm{Mn}_{2} \mathrm{MnTeO}_{6}$ with double perovskitetype structure and antiferromagnetic ordering at $36 \mathrm{~K}^{17}$

One of the most complex $\mathrm{M}_{3} \mathrm{TeO}_{6}$ compounds is $\mathrm{Co}_{3} \mathrm{TeO}_{6}$, which crystallizes in a monoclinic lithium cryolite-type structure $(C 2 / c)$ with 5 independent Co sites and shows a complex temperature-dependent incommensurate magnetic behavior. ${ }^{18-20}$ Due to the good multiferroic properties of $\mathrm{Co}_{3} \mathrm{TeO}_{6}$, this compound has arisen a lot of interest in the last few years and has been well investigated in numerous publications. ${ }^{18-24}$

Lately, we succeeded in the synthesis of a high-pressure polymorph of $\mathrm{Co}_{3} \mathrm{TeO}_{6}$ at a pressure of $6.5 \mathrm{GPa}$ and a temperature of $1070 \mathrm{~K}$. It crystallizes in the $\mathrm{Ni}_{3} \mathrm{TeO}_{6}$-type structure. Besides normal-pressure (NP) $\mathrm{Co}_{3} \mathrm{TeO}_{6}{ }^{18}$ and a monoclinic $\mathrm{CoTeO}_{4}$, that is related to the rutile structure, ${ }^{25} \mathrm{HP}-\mathrm{Co}_{3} \mathrm{TeO}_{6}$ is now the third existing cobalt tellurate modification. This work presents the synthesis, single-crystal structure and magnetic as well as magnetoelectric characterization of $\mathrm{HP}-\mathrm{Co}_{3} \mathrm{TeO}_{6}$.

\section{Experimental}

\subsection{Synthesis}

The high-pressure phase of $\mathrm{Co}_{3} \mathrm{TeO}_{6}$ was obtained via highpressure/high-temperature multianvil synthesis. In the first step single phase $\mathrm{NP}^{-} \mathrm{Co}_{3} \mathrm{TeO}_{6}$ was prepared by conventional solid state synthesis, starting from $\mathrm{Co}\left(\mathrm{NO}_{3}\right)_{2} \cdot 6 \mathrm{H}_{2} \mathrm{O}$ (Merk, 99\% p.a) and $\mathrm{H}_{6} \mathrm{TeO}_{6}$ (TCI, >99.0\%). The stoichiometric mixture was homogenized and calcined at $770 \mathrm{~K}$ for $7 \mathrm{~h}$. The intermediate product was powdered and annealed multiple times ( $7 \mathrm{~h}$ per temperature step) with temperature intervals of $100 \mathrm{~K}$ up to $970 \mathrm{~K}$, as described in literature. ${ }^{26}$

For the high-pressure/high-temperature experiment, the polycrystalline precursor was surrounded by platinum foil and placed in an 18/11-assembly crucible made of hexagonal boron nitride. The Walker module of the multianvil press, which contained the sample inside of an octahedral pressure medium, was compressed with a ramp of 72 bar $^{-1}$ to a pressure of $6.5 \mathrm{GPa}$. At synthesis pressure, the sample was heated to $1070 \mathrm{~K}$ within $5 \mathrm{~min}$ and kept at this temperature for another $20 \mathrm{~min}$. Subsequently, the sample was steadily cooled down to $670 \mathrm{~K}$ during $120 \mathrm{~min}$ to preserve better crystal quality. As soon as the heating process was terminated, the pressure was released with a ramp of $24 \mathrm{bar} \mathrm{h}^{-1}$. Afterwards, the sample was isolated by breaking the octahedral pressure medium. The powdered sample appears dark greyish to purple and is stable in air. Further information about the multianvil technique and the construction of the various assemblies can be found in literature and references therein. ${ }^{27,28}$

\subsection{Characterization}

Elemental analysis by EDX. By the use of a Jeol JSM-6010LV scanning electron microscope with a Quantax (Bruker Nano) energy-dispersive X-ray detector (EDX) for element identification, several crystals of $\mathrm{HP}-\mathrm{Co}_{3} \mathrm{TeO}_{6}$ were semiquantitatively analyzed. Three suitable regions of each crystal were selected as measurement points. The averaged experimentally observed element quantification for $\mathrm{HP}-\mathrm{Co}_{3} \mathrm{TeO}_{6}(32 \pm 3$ at\% Co: $11 \pm$ 2 at $\%$ Te: $57 \pm 3$ at $\%$ O) was near to the expected one $(30.0$ at $\%$ Co: 10.0 at\% Te: 60.0 at\% O). No additional elements were detected.

Powder and single crystal X-ray diffraction. A polycrystalline sample of $\mathrm{HP}-\mathrm{Co}_{3} \mathrm{TeO}_{6}$ was characterized by X-ray powder diffraction on a STOE Stadi P diffractometer with (111) curved Ge monochromatized $\operatorname{MoK}_{\alpha 1}$ radiation $(\lambda=70.93 \mathrm{pm})$. The powdered sample was mounted between two thin acetate films with high-vacuum grease and measured in transmission geometry. The diffraction intensities were collected by a Dectris MYTHEN2 1K microstrip detector with 1280 strips. For the Rietveld refinements the software package Diffrac ${ }^{\text {plus }}$-Topas ${ }^{\circledR}$ 4.2 (Bruker AXS, Karlsruhe, Germany) was used. The refinement is based on the parameters derived from the single-crystal structure model and the peak shapes were modeled using modified Thompson-Cox-Hastings pseudo-Voigt profiles. ${ }^{29,30}$ Instrumental contributions on reflection profiles were corrected from the refinement of $\mathrm{a} \mathrm{LaB}_{6}$ standard. ${ }^{31}$ The background was fitted with Chebychev polynomials up to the 8th order. Fig. SI1 $(\mathrm{ESI} \dagger)$ displays the results of the Rietveld refinement of $\mathrm{HP}-\mathrm{Co}_{3} \mathrm{TeO}_{6}$. The lattice parameters derived from the refinement are comparable with those received by single-crystal X-ray diffraction (see Table 1). The sample was single-phase apart from a small contamination from the BN assembly crucible.

High-temperature X-ray powder diffraction data (HT-PXRD) of $\mathrm{HP}-\mathrm{CO}_{3} \mathrm{TeO}_{6}$ were recorded with a STOE Stadi P diffractometer system (Mo- $\left.K_{\alpha 1}, \lambda=70.93 \mathrm{pm}\right)$ equipped with an image-plate detector $\left(120^{\circ}\right)$ and a STOE furnace. A milled polycrystalline sample of $\mathrm{HP}-\mathrm{Co}_{3} \mathrm{TeO}_{6}$ was filled in a silica glass capillary with a diameter of $0.3 \mathrm{~mm}$ and a wall thickness of $0.01 \mathrm{~mm}$. The furnace was heated and cooled in the range from $298 \mathrm{~K}$ to $673 \mathrm{~K}$ in steps of $100 \mathrm{~K}$. From $673 \mathrm{~K}$ to the maximum temperature of $1373 \mathrm{~K}$ the sample was heated and cooled in steps of $50 \mathrm{~K}$. The heating rate was set to $5 \mathrm{~K} \mathrm{~min}^{-1}$. After every temperature step, a diffraction pattern was recorded in the region $2-52^{\circ} 2 \theta$.

Several fragments of the crushed sample were embedded in polyfluoropolyalkylether (viscosity 1800) and suitable singlecrystal fragments were isolated under the microscope and fixed on the tip of MicroMounts ${ }^{\mathrm{TM}}$ (MiTeGen, LLC, Ithaca, NY, USA) with a diameter of $30 \mu \mathrm{m}$. Diffraction data was collected on a Bruker D8 Quest diffractometer with a Photon 100 detector system and an Incoatec microfocus source generator (multilayered optic, monochromatized $\mathrm{Mo}_{\alpha}$ radiation, $\lambda=71.073 \mathrm{pm}$ ). To optimize the collection strategies concerning $\omega$ - and $\varphi$-scans, the Apex 3 program package ${ }^{32}$ was used. As a result, a data set of the complete reciprocal sphere up to high angles $\left(\theta=37.7^{\circ}\right)$ with a high redundancy (9.28) was received. The program Saint ${ }^{32}$ was used for data processing and data reduction. Finally, an absorption correction was carried out on the semi-empirical "multi scan" approach with the program Sadabs. ${ }^{32}$

\section{Vibrational spectroscopy}

FTIR-ATR. The polycrystalline sample of $\mathrm{HP}-\mathrm{Co}_{3} \mathrm{TeO}_{6}$ was characterized by FTIR-ATR (Fourier Transformed IR - Attenuated Total Reflection) spectroscopy using a Bruker ALPHA PlatinumATR spectrometer (Bruker, Billerica, USA) equipped with a 
Table 1 Crystal data and structure refinement of $\mathrm{HP}_{-} \mathrm{CO}_{3} \mathrm{TeO}_{6}$ (standard deviations in parentheses)

\begin{tabular}{|c|c|}
\hline Empirical formula & $\mathrm{Co}_{3} \mathrm{TeO}_{6}$ \\
\hline Molar mass, $\mathrm{g} \mathrm{mol}^{-1}$ & 400.39 \\
\hline Crystal system & Trigonal \\
\hline Space group & $R 3$ (no. 146) \\
\hline Formula units per cell, $Z$ & 3 \\
\hline Powder diffractometer & STOE Stadi P \\
\hline Radiation & Mo- $K_{\alpha 1}(\lambda=70.93 \mathrm{pm})$ \\
\hline \multicolumn{2}{|l|}{ Powder data: } \\
\hline$a, \mathrm{pm}$ & $518.97(1)$ \\
\hline$c, \mathrm{pm}$ & 1381.56(1) \\
\hline$V, \AA^{3}$ & 322.24 \\
\hline Single-crystal diffractometer & Bruker D8 Quest \\
\hline Radiation & Mo- $K_{\alpha}(\lambda=71.073 \mathrm{pm})$ \\
\hline \multicolumn{2}{|l|}{ Single-crystal data: } \\
\hline$a, \mathrm{pm}$ & $519.37(6)$ \\
\hline$c, \mathrm{pm}$ & $1382.4(2)$ \\
\hline$V, \AA^{3}$ & 322.93 \\
\hline Calculated density, $\mathrm{g} \mathrm{cm}^{-3}$ & 6.18 \\
\hline Crystal size, $\mathrm{mm}^{3}$ & $0.04 \times 0.03 \times 0.03$ \\
\hline Temperature, $\mathrm{K}$ & $297(2)$ \\
\hline Absorption coefficient, $\mathrm{mm}^{-1}$ & 18.0 \\
\hline$F(000), \mathrm{e}$ & 543 \\
\hline Detector distance, mm & 40 \\
\hline$\theta$ range, deg & $4.4-37.7$ \\
\hline Range in $h k l$ & $\pm 8, \pm 8, \pm 23$ \\
\hline Reflections total & 3596 \\
\hline Data/ref. parameters & $773 / 32$ \\
\hline Reflections with $I \geq 2 \sigma(I)$ & 773 \\
\hline$R_{\mathrm{int}}, R_{\sigma}$ & $0.0236,0.0176$ \\
\hline Goodness-of-Fit on $F^{2}$ & 1.114 \\
\hline Absorption correction & Multi-scan ${ }^{32}$ \\
\hline$R_{1} / \mathrm{w} R_{2}$ for $I \geq 2 \sigma(I)$ & $0.0150 / 0.0374$ \\
\hline$R_{1} / \mathrm{w} R_{2}$ (all data) & $0.0150 / 0.0374$ \\
\hline Flack parameter & $0.04(5)$ \\
\hline Largest diff. peak/hole, e $\AA^{-3}$ & $0.94 /-0.80$ \\
\hline Extinction coefficient & $0.0035(4)$ \\
\hline Transmission min./max. & $0.6489 / 0.7474$ \\
\hline
\end{tabular}

$2 \times 2 \mathrm{~mm}$ diamond ATR-crystal and a DTGS detector, in the spectral range of $400-4000 \mathrm{~cm}^{-1}$. For the measurement, 320 scans were acquired and a data correction for atmospheric influences was performed using the Opus 7.2 software. $^{33}$

$U V$-Vis. A diffuse reflectance spectrum of the powdered sample was recorded in the range of 360 to $830 \mathrm{~nm}$, using an Agilent Cary 5000 UV-Vis spectrometer equipped with an integrating sphere (DRA-2500), a D65 as standard illuminant and a $10^{\circ}$ complementary

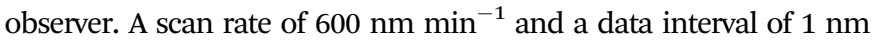
were applied and $\mathrm{BaSO}_{4}$ was used as white standard. Via the Kubelka-Munk (KM) function the optical absorbance was calculated from the generated reflectance data and the band gap was determined using Tauc-plots. ${ }^{34,35}$

\section{Physical property measurements}

Magnetic properties. The polycrystalline sample of $\mathrm{HP}-\mathrm{Co}_{3} \mathrm{TeO}_{6}$ was enclosed in a polyethylene (PE) capsule. Magnetization $M(T, H)$ measurements were performed on a Quantum Design Physical Property Measurement System (PPMS) using the Vibrating Sample Magnetometer (VSM) unit. The sample was investigated in the temperature range of $2.5-300 \mathrm{~K}$ with magnetic fields up to $80 \mathrm{kOe}$.

Heat capacity. The specific heat of a $\mathrm{HP}-\mathrm{Co}_{3} \mathrm{TeO}_{6}$ specimen with $m=16.03(2) \mathrm{mg}$ was measured in a PPMS-9 at magnetic fields of 0 Oe, 100 Oe and $10 \mathrm{kOe}$, respectively. A step width of $5 \mathrm{~K}$ was chosen in the temperature range 300-80 K, whereas between 80 and $3 \mathrm{~K} C_{\mathrm{P}}$ values were recorded with $1 \mathrm{~K}$ steps. The contribution of the thermal conduction grease $(0.13 \mathrm{mg}$ Apiezon N) was subtracted prior to data evaluation.

Magnetoelectric properties. For the magnetoelectric investigations gold contacts of $100 \mathrm{~nm}$ thickness were sputtered on both sides of the disk-shaped $\mathrm{Co}_{3} \mathrm{TeO}_{6}$ sample $(\varnothing \approx 3 \mathrm{~mm}, h \approx 1 \mathrm{~mm}$ ) using a Cressington Sputter Coater 108auto. ME measurements were carried out in the temperature range $65 \mathrm{~K}$ to $10 \mathrm{~K}$ with $5 \mathrm{~K}$ intervals in a PPMS-9, using the self-designed setup described in literature. ${ }^{36}$ The static magnetic field was varied between $-17 \mathrm{kOe}$ and $17 \mathrm{kOe}$ and a collinear ac field of $H_{\mathrm{ac}}=10 \mathrm{Oe}$ with a frequency of $900 \mathrm{~Hz}$ was superimposed. The ME coefficient $\alpha_{\mathrm{ME}}$ was calculated from the real part (in-phase) of the ac-voltage $U_{\mathrm{ac}}$ according to eqn (1) using a lock-in technique.

$$
\alpha_{\mathrm{ME}}=\frac{U_{\mathrm{ac}}}{H_{\mathrm{ac}} \cdot h}
$$

Data analysis was carried out using the peak analyzing tool of OriginPro 2018G. ${ }^{37}$

\section{Results and discussion}

\subsection{Structure refinements}

$\mathrm{HP}-\mathrm{Co}_{3} \mathrm{TeO}_{6}$ crystallizes in the trigonal crystal system and the systematic extinctions were in agreement with the acentric space group $R 3$. The initial positional parameters were determined by the "Intrinsic Phasing" method," implemented in the Apex 3 program package. $^{32}$ Full-matrix least-squares refinements based on $F^{2}$, yielded the exact atom positions. ${ }^{39,40}$ Finally, all atoms were refined with anisotropic displacement parameters and the occupation parameters were refined in separate series of least-squares cycles in order to verify the correct composition. The correctness of the space group was checked with the Addsym $^{41}$ routine of the Platon program package. ${ }^{42}$ Addsym detected a pseudo centre of symmetry which implicates the structural relationship of $\mathrm{HP}-\mathrm{Co}_{3} \mathrm{TeO}_{6}$ to corundum $(R \overline{3} c)$. In contrast to corundum, the oxygen ions of $\mathrm{HP}-\mathrm{Co}_{3} \mathrm{TeO}_{6}$ are only approximately hexagonally close-packed. Co and Te occupy four $3 a$ sites (corresponding to the $12 c$ site of $\mathrm{Al}$ in the corundum structure) in an ordered manner. The oxygen atoms in $\mathrm{Co}_{3} \mathrm{TeO}_{6}$ occupy two general positions $(9 b)$ breaking the inversion symmetry and leading to space group $R 3$. Furthermore, the Flack parameter of 0.04(5) verifies the presence of an acentric crystal structure. Experimental details, the positional parameters, anisotropic displacement parameters, interatomic distances, and angles are listed in Tables 1, 2 and in Tables SI1-SI3 of the ESI. $\dagger$

CSD $2032321\left(\mathrm{HP}-\mathrm{Co}_{3} \mathrm{TeO}_{6}\right)$ contains the $\mathrm{ESI} \dagger$ data for this paper.

\subsection{Crystal chemistry}

$\mathrm{HP}_{-} \mathrm{Co}_{3} \mathrm{TeO}_{6}$ crystallizes in the well-known $\mathrm{Ni}_{3} \mathrm{TeO}_{6}$-type structure. ${ }^{43}$ The structure-type is a superstructure of corundum, therefore the tellurium $\left(\mathrm{Te}^{6+}\right)$ and the three crystallographic 
Table 2 Atomic coordinates, occupation, and isotropic equivalent displacement parameters $U_{\text {eq }}\left(\AA^{2}\right)$ for $\mathrm{HP}-\mathrm{Co}_{3} \mathrm{TeO}_{6}$ (space group: $R 3$ ). $U_{\text {eq }}$ is defined as one third of the trace of the orthogonalized $U_{i j}$ tensor (standard deviations in parentheses). Wyckoff positions: Co 3a, Te $3 a$ and $O 9 b$

\begin{tabular}{llllll}
\hline Atom & $x$ & $y$ & $z$ & SOF & $U_{\text {eq }}$ \\
\hline Te & 0 & 0 & $0.00015(5)$ & 1 & $0.0045(1)$ \\
Co1 & 0 & 0 & $0.20819(6)$ & 1 & $0.0069(2)$ \\
Co2 & 0 & 0 & $0.48924(12)$ & 1 & $0.0076(4)$ \\
Co3 & 0 & 0 & $0.70046(7)$ & 1 & $0.0076(2)$ \\
O1 & $0.28753(8)$ & $0.2955(8)$ & $0.0898(2)$ & 1 & $0.0075(5)$ \\
O2 & $0.36622(8)$ & $0.0004(7)$ & $0.2634(2)$ & 1 & $0.0073(5)$
\end{tabular}

distinct cobalt $\left(\mathrm{Co}^{2+}\right)$ sites are sixfold coordinated by oxygen ions (see Fig. 1 and 2) in a distorted octahedral geometry.

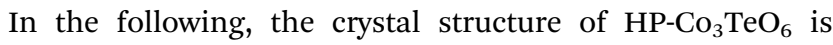
compared to the crystal structure of $\mathrm{NP}^{-} \mathrm{Co}_{3} \mathrm{TeO}_{6}$ and to the isotypic compound $\mathrm{Ni}_{3} \mathrm{TeO}_{6}$. Moreover, the pressure-induced phase transition is discussed concerning the observed structural changes.

At ambient conditions, $\mathrm{NP}-\mathrm{Co}_{3} \mathrm{TeO}_{6}$ crystallizes in a monoclinic lithium cryolite-type structure with the space group $\mathrm{C2} / \mathrm{c}$. In contrast to $\mathrm{HP}-\mathrm{Co}_{3} \mathrm{TeO}_{6}$, the oxygen atoms of $\mathrm{NP}-\mathrm{Co}_{3} \mathrm{TeO}_{6}$ are not only hexagonally closed packed, but also show cubic packing elements, which results in a mixed approximately double hexagonal-cubic close packed hhchhc six-layer sequence along the $a$-axis, ${ }^{18}$ as shown in Fig. 2a. Due to the different packing of the oxygen atoms, there are nine distinct crystallographic oxygen sites, three are located on the $c$-layers and six on the $h$-layers. The tellurium cations, which both have an octahedral coordination geometry in NP- and HP- $\mathrm{Co}_{3} \mathrm{TeO}_{6}$, split into two distinct crystallographic sites for $\mathrm{NP}-\mathrm{Co}_{3} \mathrm{TeO}_{6}$. Oxygen atoms coordinate only three of the five crystallographically distinct cobalt sites of $\mathrm{NP}-\mathrm{Co}_{3} \mathrm{TeO}_{6}$ in a more or less distorted octahedral manner. As a
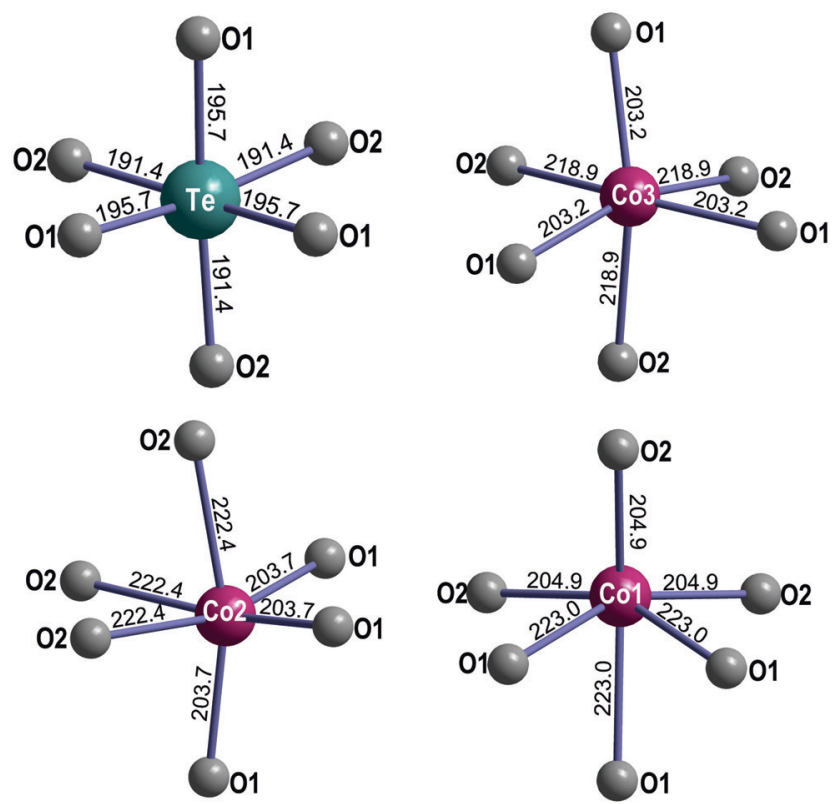

Fig. 1 The coordination spheres of the $\mathrm{CoO}_{6}$ - and the $\mathrm{TeO}_{6}$-octahedra. Distances are given in (pm). result of a markedly extended $\mathrm{Co} 3-\mathrm{O} 2$ distance, the $\mathrm{Co} 3$ site is described in a square-pyramidal coordination geometry and Co5 even exhibit only a tetrahedral coordination sphere. ${ }^{18}$

Due to the pressure impact, the coordination numbers of cobalt and oxygen partially increase to form the higher symmetric $\mathrm{Ni}_{3} \mathrm{TeO}_{6}$-type structure of $\mathrm{HP}^{-} \mathrm{CO}_{3} \mathrm{TeO}_{6}$, which is built by less distorted $\mathrm{CoO}_{6}$ - and $\mathrm{TeO}_{6}$-octahedra (see Fig. $2 \mathrm{~b}-\mathrm{d}$ ). This increase in the coordination number is in line with the pressure coordination rule, the subsequent increase in the interatomic distances of cobalt and oxygen satisfies the pressure distance rule. ${ }^{44}$ This is most evident from the shortest $\mathrm{Co}-\mathrm{O}$ contacts of

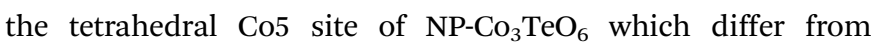
192.9(4) to 199.8(3) pm. While adapting the $\mathrm{Ni}_{3} \mathrm{TeO}_{6}$-type structure, the contacts elongate to an average $\mathrm{Co}-\mathrm{O}$ distance of $212.7 \mathrm{pm}$ in octahedral coordination sphere. ${ }^{18}$ This is accompanied by a density increase of approximately $5 \%$. The $\mathrm{TeO}_{6}$-octahedra are isolated, i.e., not paired or linked to other $\mathrm{TeO}_{6}$-octahedra in both

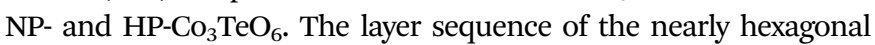
layers can be seen in Fig. $2 \mathrm{c}$ and d. As a result of the high valence of tellurium, the $\mathrm{Te}^{6+}$-cations are located at a maximum distance from the cobalt and nickel cations. Therefore, the shared edges and faces of the $\mathrm{TeO}_{6}$-octahedra with $\mathrm{CoO}_{6}$ - or $\mathrm{NiO}_{6}$-octahedra of NP- $\mathrm{Co}_{3} \mathrm{TeO}_{6}, \mathrm{HP}-\mathrm{Co}_{3} \mathrm{TeO}_{6}$ and $\mathrm{Ni}_{3} \mathrm{TeO}_{6}$ show significantly shorter O-O distances of 258.3(5)-264.6(5) pm, 262.3(8)-266.8(5) pm and $260.9(8)-266.6(8) \mathrm{pm}$ than the non-shared edges and faces of 269.5(5)-286.8(5) pm, 277.1(5)-286.0(7) pm, and 278.7(8)288.1(9) pm, respectively. ${ }^{18,45}$

All values of bond lengths and interatomic angles of $\mathrm{Ni}_{3} \mathrm{TeO}_{6}$ and $\mathrm{HP}-\mathrm{Co}_{3} \mathrm{TeO}_{6}$ and their discrepancies are given in Tables SI2 and SI3 (ESI $\dagger$ ), respectively.

Additionally, bond valence sums were calculated according to both, the bond-length/bond-strength $(\Sigma V)^{46-48}$ and the CHARDI $(\Sigma Q)$ concept $^{49}$ (Table 3). The values obtained by both concepts are in accordance to the expected formal ionic charges of $\mathrm{Co}^{2+}, \mathrm{Te}^{6+}$ and $\mathrm{O}^{2-}$.

The Madelung part of lattice energy of $\mathrm{HP}^{-\mathrm{Co}_{3} \mathrm{TeO}_{6}(M A P L-}$ $E_{\text {ter }}=39195 \mathrm{~kJ} \mathrm{~mol}^{-1}$ ) was estimated by MAPLE value calculations ${ }^{50,51}$ and was compared to the sum of the MAPLE values of the binary educts $\mathrm{CoO}^{52}$ (CoO: $4555 \mathrm{~kJ} \mathrm{~mol}^{-1}$ ) and $\mathrm{TeO}_{3}{ }^{53}\left(\mathrm{TeO}_{3}: 25794 \mathrm{~kJ} \mathrm{~mol}^{-1}\right)$ as described in eqn (2).

$M A P L E_{\mathrm{bin}}=3 \cdot M A P L E_{\mathrm{CoO}}+M A P L E_{\mathrm{TeO} 3}=39459 \mathrm{~kJ} \mathrm{~mol}^{-1}$

A discrepancy of $M A P L E_{\mathrm{ter}}-M A P L E_{\mathrm{bin}}$ of $\Delta=264 \mathrm{~kJ} \mathrm{~mol}^{-1}$, or $0.7 \%$ was observed.

\subsection{Temperature-dependent X-ray diffraction}

In general, the heating of metastable high-pressure phases leads to a back-transformation to the normal-pressure modifications or to a decomposition. Temperature dependent powder X-ray investigations are an excellent method to follow these transformations. As displayed in Fig. 3, HP-

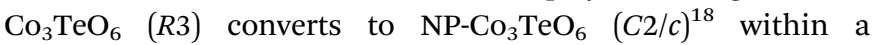
small temperature range above $1070 \mathrm{~K}$. Both phases coexist within a temperature interval of $50 \mathrm{~K}$ and above $1120 \mathrm{~K}$ only

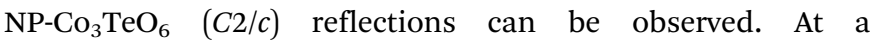


a

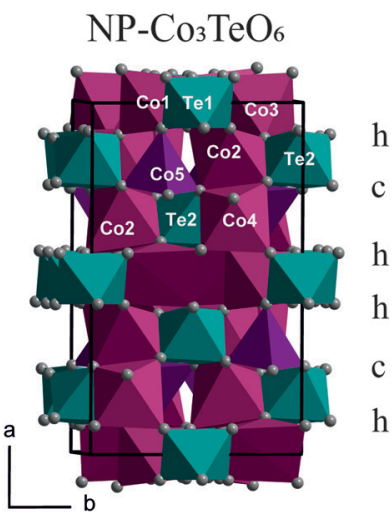

C

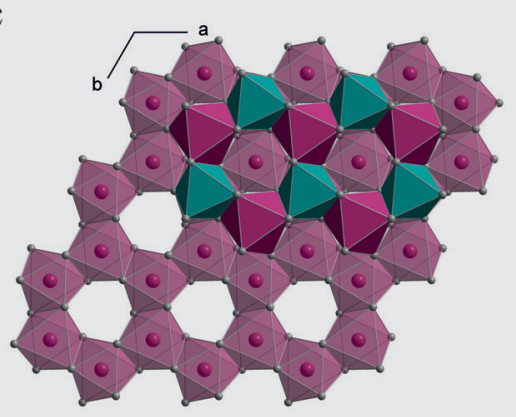

b

b
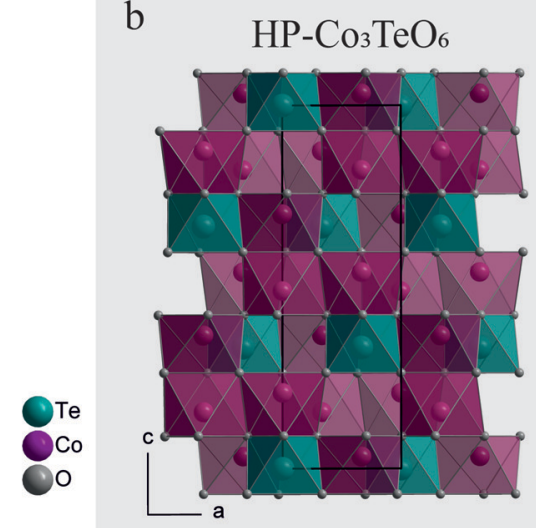

d

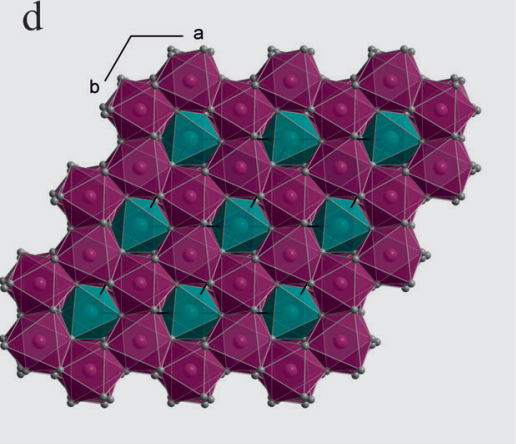

Fig. 2 The crystal structure of $\mathrm{NP}_{-} \mathrm{CO}_{3} \mathrm{TeO}_{6}$ is shown in (a). The five different Co coordination polyhedra are marked. The crystal structure of HP$\mathrm{CO}_{3} \mathrm{TeO}_{6}$ with a view along the $b$-axis and view along the $c$-axis are given in (b) and (d), respectively. $\mathrm{TeO}_{6}$ - and $\mathrm{CoO}_{6}$-octahedra are drawn in violet and teal. (c) Illustrates the stacking of the honeycomb-ordered layers along the $c$-axis.

Table 3 Charge distributions according to the bond length/bond strength $(\Sigma V)$ and the CHARDI $(\Sigma Q)$ concept of $\mathrm{HP}-\mathrm{CO}_{3} \mathrm{TeO}_{6}$

\begin{tabular}{lllllll}
\hline & $\mathrm{Co} 1$ & $\mathrm{Co} 2$ & $\mathrm{Co} 3$ & $\mathrm{Te}$ & $\mathrm{O} 1$ & $\mathrm{O} 2$ \\
\hline$\Sigma V$ & +1.84 & +1.89 & +1.98 & +5.72 & -1.92 & -1.89 \\
$\Sigma Q$ & +2.00 & +2.00 & +2.00 & +6.00 & -2.02 & -1.98 \\
\hline
\end{tabular}

temperature of $1270 \mathrm{~K}$, the compound starts to decompose to $\mathrm{CoTeO}_{3} \cdot{ }^{54} \mathrm{~A}$ subsequent reaction with the silica glass capillary finally leads to silicon dioxide, cobalt(II)oxide and $\mathrm{Co}_{2} \mathrm{SiO}_{4}$. During cooling, no reflections could be assigned to tellurium containing phases, indicating that either amorphous compounds are formed or that tellurium has completely evaporated due to the open system.

\subsection{Spectroscopic characterization}

FT-IR. The FT-IR spectra in Fig. 4 shows three strong bands in the range of $400-700 \mathrm{~cm}^{-1}$, that can be assigned to $\nu_{3}, \nu_{4}$ and $\nu_{5}$ modes $\left(C_{3}\right.$ site symmetry) of the $\mathrm{TeO}_{6}$-octahedra. The assignment of the bands was done according to the isotypic compound $\mathrm{Mg}_{3} \mathrm{TeO}_{6}{ }^{55}$ and $\mathrm{Ni}_{3} \mathrm{TeO}_{6} \cdot{ }^{56}$ As a consequence of the acentric space group $R 3$, the site symmetry of the $\mathrm{TeO}_{6}$ octahedra is $C_{3}$ instead of $O_{\mathrm{h}}$ and the $\nu_{3}, \nu_{4}$, and $\nu_{5}$ vibrations are split. Furthermore, due to the acentric crystal structure the

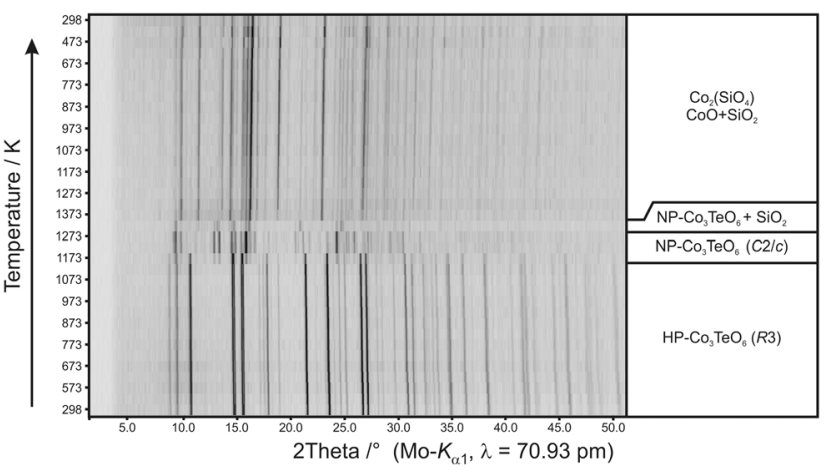

Fig. 3 Temperature dependent $\mathrm{X}$-ray powder diffraction of HP$\mathrm{CO}_{3} \mathrm{TeO}_{6}$

$\nu_{1}, \nu_{2}$, and $\nu_{5}$ vibrations are also IR active but the infrared intensities are expected to be low. The $\nu_{2}$ mode is only visible as a weak absorption at $579 \mathrm{~cm}^{-1}$ and the $\nu_{1}$ overlap with the strong $\nu_{3}$ modes.

A precise identification is thereby impeded. At $510 \mathrm{~cm}^{-1}$ the Co-O stretching modes of the $\mathrm{CoO}_{6}$-octahedra along the $a b$ plane and the $\nu_{4}$ modes of the $\mathrm{TeO}_{6}$-octahedra overlap. ${ }^{57,58}$ It should be kept in mind that the modes are complex framework vibrations and an allocation to isolated stretching or bending 


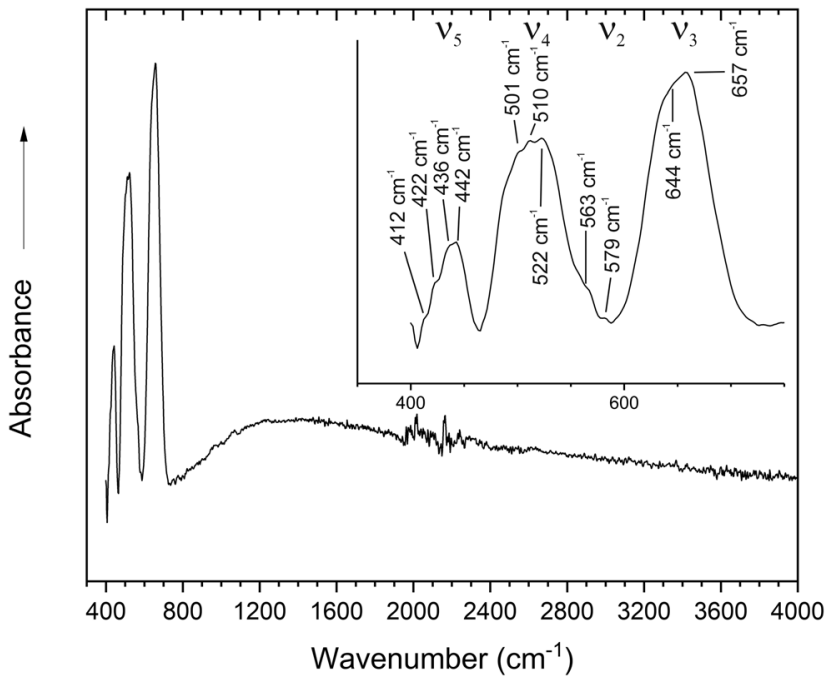

Fig. 4 FT-IR-spectra of $\mathrm{HP}-\mathrm{CO}_{3} \mathrm{TeO}_{6}$.

modes of the $\mathrm{TeO}_{6}$ - and $\mathrm{CoO}_{6}$-units is only possible in a first approximation, as calculations showed. ${ }^{55}$

UV-Vis. The reflectance UV-Vis spectra of $\mathrm{HP}^{-\mathrm{Co}_{3} \mathrm{TeO}_{6}}$ shows two peaks at $460 \mathrm{~nm}$ and $675 \mathrm{~nm}$ (see Fig. 5) indicating a reflection of blue and red light. The dark purple

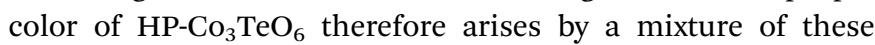
two peaks.

To evaluate the band gap, the Kubelka-Munk (KM) function ${ }^{35}$ and the Tauc $\operatorname{plot}^{34}$ were used. The KM function $(F(R))$ is calculated according to eqn (3), in which $R$ represents the reflectance, $K$ the absorption coefficient and $S$ the scattering coefficient. To generate the Tauc plots, the factor $(F(R) \cdot h \nu)^{n}$ was plotted against the photon energy. For indirect and direct band gaps, $n$ was set to $n=2$ and $n=0.5$, respectively. The band gap values $E_{\mathrm{g}}$ were determined by the tangent method as shown in Fig. 5 (inset). Since the reflectance spectra exhibited two absorption peaks, the onset which led to the

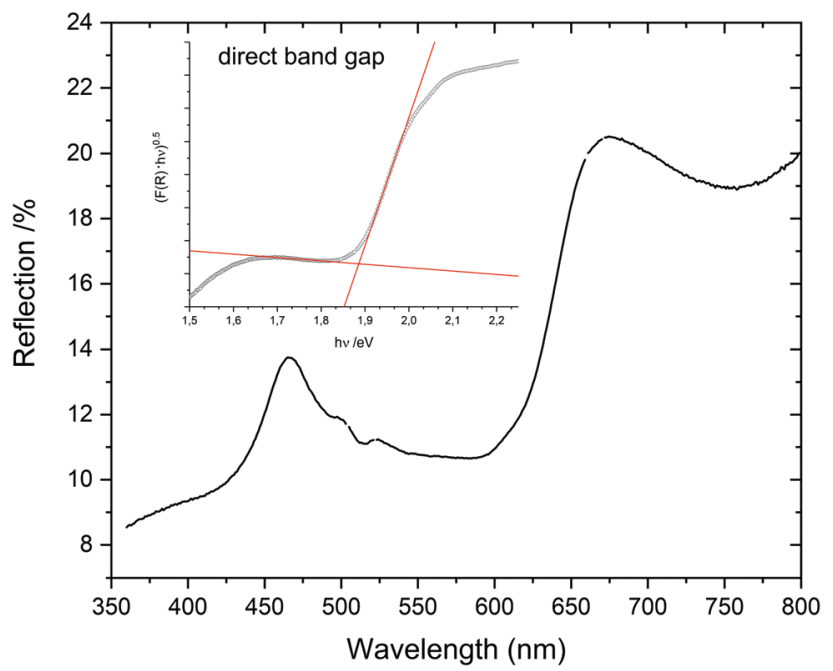

Fig. 5 UV-Vis reflectance spectra of $\mathrm{HP}-\mathrm{CO}_{3} \mathrm{TeO}_{6}$ and Tauc plot (inset) assuming a direct band gap. lowest band gap energies was chosen.

$$
F(R)_{\mathrm{KM}}=\frac{K}{S}=\frac{(1-R)^{2}}{2 R}
$$

For the direct and the indirect (see Fig. SI2 of the ESI $\dagger$ ) band gap of $\mathrm{HP}-\mathrm{Co}_{3} \mathrm{TeO}_{6}$, values of $E_{\mathrm{g}}=1.88 \mathrm{eV}$ and $E_{\mathrm{g}}=1.91 \mathrm{eV}$ were determined.

\subsection{Physical properties}

Magnetic properties. Magnetic susceptibility measurements were conducted in a zero-field-cooled (ZFC) mode between 3 and $300 \mathrm{~K}$ with an external field strength of $10 \mathrm{kOe}$. A data correction was performed to account for diamagnetic contributions of the PE capsule and of the constituent ions leading to $\chi^{\mathrm{dia}}\left(\mathrm{Co}_{3} \mathrm{TeO}_{6}\right)=-120 \times 10^{-6} \mathrm{emu} \mathrm{mol}^{-1}\left(\chi^{\mathrm{dia}}\left(\mathrm{Co}^{2+}\right)=-12 \times\right.$ $10^{-6} \mathrm{emu} \mathrm{\textrm {mol } ^ { - 1 }} ; \chi^{\mathrm{dia}}\left(\mathrm{Te}^{6+}\right)=-12 \times 10^{-6} \mathrm{emu} \mathrm{mol}^{-1}$ and

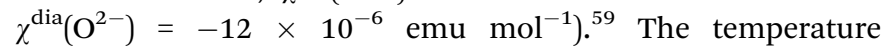
dependent values of $\chi$ and $\chi^{-1}$ are illustrated in Fig. 6 (top). Beneath $50 \mathrm{~K}$ two phenomena are apparent, while between $100 \mathrm{~K}$ and $300 \mathrm{~K}$ a Curie-Weiss behavior is observed. Based on the inverse susceptibility the effective magnetic moment was calculated and a value of $\mu_{\text {eff }}=5.28(1) \mu_{\mathrm{B}}$ was obtained. This magnetic moment is higher than the expected moment of $\mathrm{Co}^{2+}$ ( $\mathrm{d}^{7}$ high-spin) of $3.88 \mu_{\mathrm{B}}$. Therefore, a high degree of spin-orbit interactions can be assumed. A Weiss constant of $\theta_{\mathrm{P}}=-63.4(1) \mathrm{K}$ indicates an antiferromagnetic interaction in the paramagnetic region.

Low-field measurements (100 Oe) between 2.5 and $100 \mathrm{~K}$ (Fig. SI3, ESI $\dagger$ ) revealed four anomalies at $T_{1} \approx 21 \mathrm{~K}, T_{2} \approx 52 \mathrm{~K}$, $T_{\mathrm{N}, 3}=58.2(1) \mathrm{K}$ and $T_{4} \approx 80 \mathrm{~K}$. The anomaly at $T_{\mathrm{N}}=58.2(1) \mathrm{K}$ can be clearly assigned to an antiferromagnetic ordering, the other phenomena still have to be clarified.

The magnetization isotherms (see Fig. 6, middle) below $T_{\mathrm{N}}=$ 58.2(1) K show a sigmoidal shape due to a spin-flop-type transition (meta-magnetic step, spin reorientation). The negative peak of the derivation of the magnetic isotherm at $3 \mathrm{~K}$ (red), reveals a critical field of $H_{\text {crit }}=10.8(1)$ kOe required for the spinflop-type transition ( $\uparrow \downarrow \uparrow \downarrow \rightarrow \uparrow \uparrow \uparrow \uparrow)$. At even higher fields another kink of the magnetization is visible, leading to a flattening of the trace of the magnetization. The magnetization continuously rises after the meta-magnetic step, due to an ongoing reorientation of the spins in the polycrystalline material. Around $\sim 55 \mathrm{kOe}$, it seems like the majority of the spins has been parallelized causing saturation. The saturation magnetization of $\mu_{\mathrm{sat}}=0.88(1) \mu_{\mathrm{B}}$ at $3 \mathrm{~K}$ and $80 \mathrm{kOe}$ is far beneath the estimated value of $\mu_{\mathrm{cal}, \mathrm{sat}}=3.87 \mu_{\mathrm{B}}$, originating from the polycrystalline sample.

Specific heat. To further examine the magnetic and magnetoelectric transition (see below) temperatures of $\mathrm{HP}_{-} \mathrm{Co}_{3} \mathrm{TeO}_{6}$, measurements of the heat capacity were performed at 0 Oe, 100 Oe and 10 kOe. The results were very similar and shown in comparison in the ESI, $\dagger$ Fig. SI4. At $300 \mathrm{~K}$ the specific heat of 211(1) $\mathrm{J} \mathrm{mol}^{-1} \mathrm{~K}^{-1}$ comes close to the Dulong-Petit value of $C_{\mathrm{P}}=$ $3 R \times N \approx 250 \mathrm{~J} \mathrm{~mol}^{-1} \mathrm{~K}^{-1}(N=10$, reflecting the 10 atoms per formula unit of $\mathrm{Co}_{3} \mathrm{TeO}_{6}$ ). 

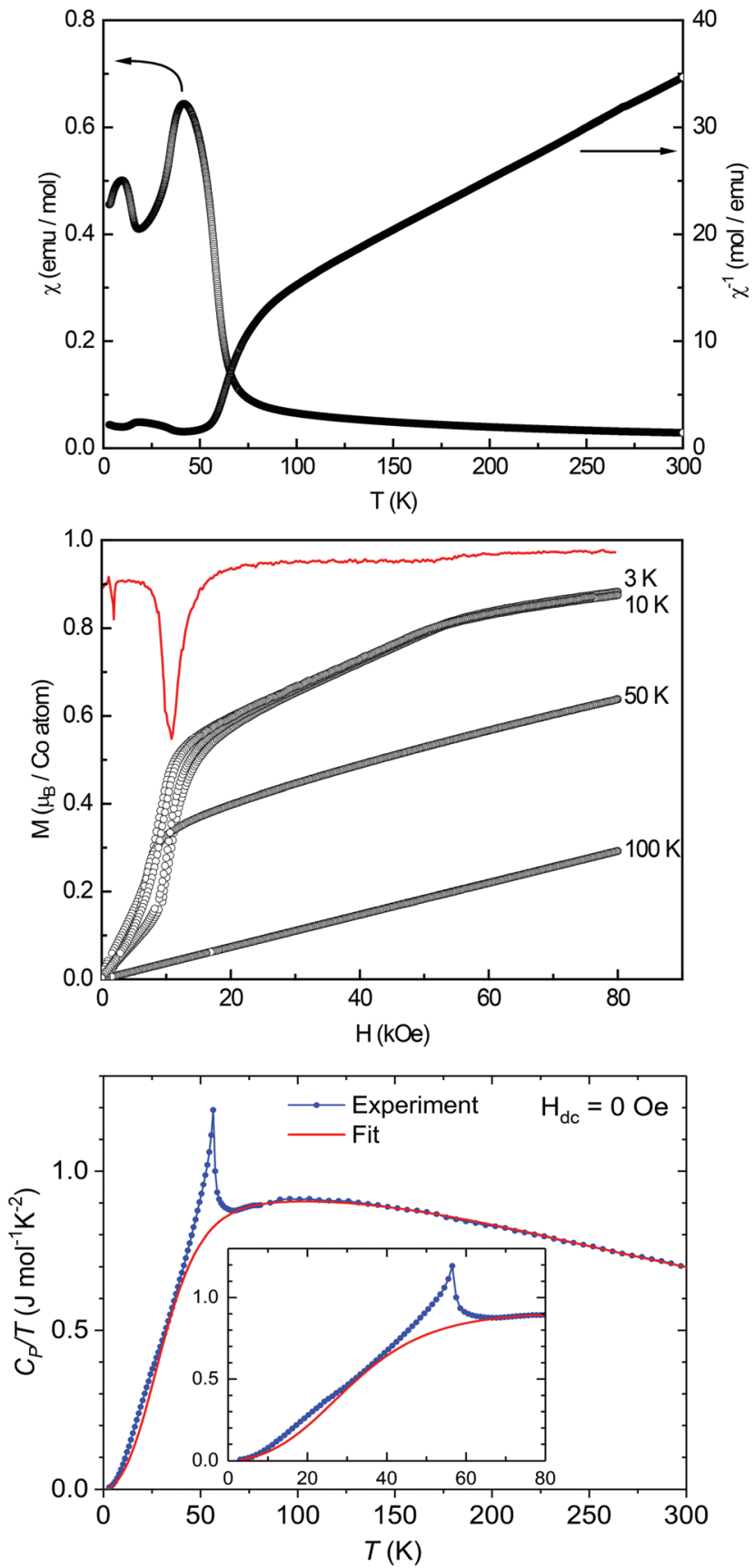

Fig. 6 Magnetic properties of $\mathrm{HP}-\mathrm{CO}_{3} \mathrm{TeO}_{6}$ : susceptibility and inverse susceptibility $\left(\chi\right.$ and $\left.\chi^{-1}\right)$, measured in an external field strength of $10 \mathrm{kOe}$ (top); magnetization isotherms recorded at 3, 10, and $50 \mathrm{~K}$, the derivative $\mathrm{d} M / \mathrm{d} H$ is depicted in red (middle); temperature dependence of $\mathrm{C}_{\mathrm{P}} / \mathrm{T}$ of $\mathrm{HP}-\mathrm{CO}_{3} \mathrm{TeO}_{6}$ at zero field (blue line and circles) with the corresponding Einstein-Debye fit (red line) (bottom).

Fig. 6 (bottom) exhibits exemplarily the temperature dependence of $C_{\mathrm{P}} / T$ for the measurement at zero field. To account for the lattice (phonon) contribution the data was fitted using a model with one Debye and two Einstein terms with a weighting of $4: 3: 3$, similar to the ones described in literature. ${ }^{60-62}$ The weighting scheme was chosen to keep the model as simple as possible (i.e., to reduce the number of refinable parameters) while being physically meaningful. The fourfold Debye term can be considered to reflect the motion of the heavy atoms ( $3 \mathrm{Co}, 1 \mathrm{Te}$ ), while the two threefold Einstein terms may be assigned to the bending and stretching modes of oxygen atoms. We emphasize, though, that we do not attempt to derive any physical information from the fit. The temperature interval $10-80 \mathrm{~K}$ in which the magnetic transitions occur was excluded from the fit. For the Debye and Einstein contributions, the following characteristic temperatures were obtained: $\Theta_{\mathrm{D}}=$ $247 \mathrm{~K}, \Theta_{\mathrm{E} 1}=494 \mathrm{~K}, \Theta_{\mathrm{E} 2}=795 \mathrm{~K}$.

The difference between $C_{\mathrm{V}}$ and $C_{\mathrm{P}}$ was considered using the Nernst-Lindemann relation $C_{\mathrm{P}}-C_{\mathrm{V}}=A \cdot C_{\mathrm{P}}{ }^{2} \cdot T$ resulting in $A=$ $8.76 \times 10^{-7} \mathrm{~mol} \mathrm{~K}^{-1}$. As shown in Fig. 6 (bottom), a sharp and intense signal occurs around $56 \mathrm{~K}$ and a second smaller, broader one at $c a .20 \mathrm{~K}$. These transitions can more clearly be seen as peaks in Fig. 7, which shows on the left scale the magnetic contribution $C_{\mathrm{P}, \mathrm{mag}} / T=C_{\mathrm{P}} / T-C_{\mathrm{P}, \text { lattice }} / T$. The obtained characteristic temperatures (taken from the peak maxima) are listed in Table 4 and are in good accordance with the values of $T_{\mathrm{N}}$ and $T_{1}$ determined from the magnetic investigations. Around $80 \mathrm{~K}$, where an additional magnetic anomaly was observed (Fig. SI3, ESI $\dagger$ ), a tiny step-like feature appears.

Compared to the NP-modification of $\mathrm{Co}_{3} \mathrm{TeO}_{6}$ remarkable differences are found. $\mathrm{NP}-\mathrm{Co}_{3} \mathrm{TeO}_{6}$ shows a rather small and diffuse $C_{\mathrm{P}}$ peak at $26 \mathrm{~K}$ and a sharp, much more intense one at $16 \mathrm{~K}^{20,63,64}$

On the other hand, the antiferromagnetic ordering temperature of $\mathrm{HP}_{-\mathrm{Co}_{3}} \mathrm{TeO}_{6}$ is comparable to the one of $\mathrm{Ni}_{3} \mathrm{TeO}_{6}\left(T_{\mathrm{N}}=52 \mathrm{~K}^{9}\right)$, which possesses a similar structure, indicating a strong correlation between crystal structure and Néel-temperature of the tellurates as reported. $^{64}$

It is to be noted that the $C_{\mathrm{P}}$ measurements of $\mathrm{HP}_{-} \mathrm{Co}_{3} \mathrm{TeO}_{6}$ are closely related to the magnetoelectric investigations described below, in which measurable ME voltages were only detected in the temperature regime between $T_{\mathrm{N}}$ and $T_{1}$. The values listed in Table 4 show that $T_{\mathrm{N}}$ of $\mathrm{HP}-\mathrm{Co}_{3} \mathrm{TeO}_{6}$ remains unaffected by the external magnetic field ( $56 \pm 0.5 \mathrm{~K})$ although

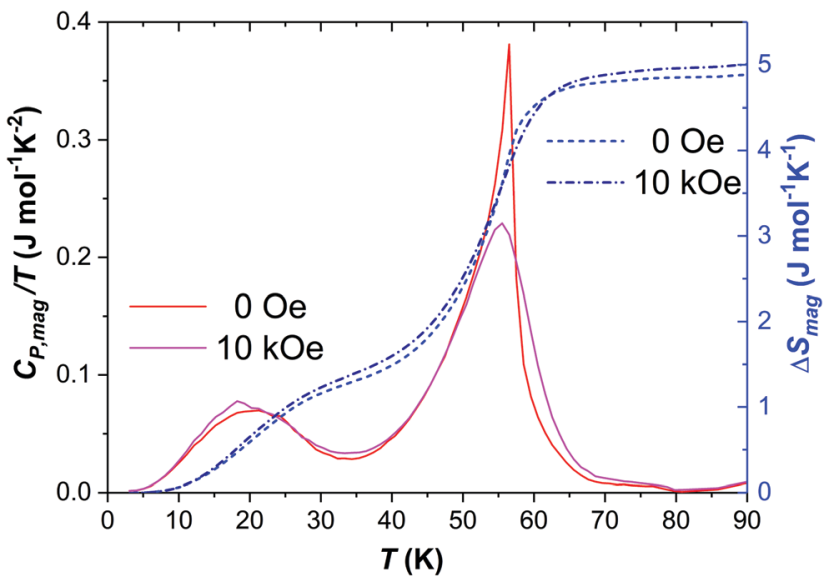

Fig. 7 Magnetic contribution to $C_{\mathrm{p}} / T$ (solid lines, left scale) and magnetic entropy (dashed lines, right scale). 
Table 4 Transition temperatures $\left(T_{N}, T_{1}\right)$ and calculated entropy values for $\mathrm{HP}-\mathrm{Co}_{3} \mathrm{TeO}_{6}$

\begin{tabular}{|c|c|c|c|c|c|c|}
\hline Substance & $H(\mathrm{Oe})$ & $T_{\mathrm{N}}(\mathrm{K})$ & $\Delta S_{\mathrm{N}}\left({ }^{a}\right)$ & $T_{1}(\mathrm{~K})$ & $\Delta S_{1}\left({ }^{a}\right)$ & $\Delta S_{\text {mag }}\left({ }^{a}\right)$ \\
\hline $\mathrm{HP}-\mathrm{Co}_{3} \mathrm{TeO}_{6}$ & 0 & $56.5(5)$ & 3.5 & $20.2(5)$ & 1.3 & 4.8 \\
\hline $\mathrm{HP}-\mathrm{Co}_{3} \mathrm{TeO}_{6}$ & 100 & $56.5(5)$ & 3.5 & $20.2(5)$ & 1.3 & 4.8 \\
\hline $\mathrm{HP}-\mathrm{Co}_{3} \mathrm{TeO}_{6}$ & 10000 & $55.5(5)$ & 3.5 & $18.2(5)$ & 1.4 & 4.9 \\
\hline $\mathrm{NP}-\mathrm{Co}_{3} \mathrm{TeO}_{6}^{20,63,64}$ & 0 & 26 & - & 16 & - & 8.9 \\
\hline $\mathrm{Ni}_{3} \mathrm{TeO}_{6}{ }^{6-8,64}$ & 0 & 52 & - & - & - & - \\
\hline
\end{tabular}

the corresponding peak in $C_{\mathrm{P}}$ clearly broadens at $10 \mathrm{kOe}$. In contrast, the value of $T_{1}$ decreases by $c a .2 \mathrm{~K}$ when $H$ is raised from 100 Oe to $10 \mathrm{kOe}$.

The right scale of Fig. 7 shows the low temperature region of the magnetic contribution to the entropy according to $\Delta S_{\mathrm{mag}}=$ $\int_{0}^{T} \frac{C_{\mathrm{P}, \mathrm{mag}}}{T} \mathrm{~d} T$ and in Table 4 the numerical values are listed. The two transitions at $T_{1}$ and $T_{\mathrm{N}}$ correspond to entropy changes of $\approx 1.4 \mathrm{~J} \mathrm{~mol}^{-1} \mathrm{~K}^{-1}$ and $\approx 3.5 \mathrm{~J} \mathrm{~mol}^{-1} \mathrm{~K}^{-1}$, respectively, resulting in a total $\Delta S_{\text {mag }} \approx 4.9 \mathrm{~J} \mathrm{~mol}^{-1} \mathrm{~K}^{-1}$. As visible from Fig. SI4 (ESI $\dagger$ ) and Table 4 very similar values were obtained for the magnetic entropy change for all three external magnetic fields.

For an ordering spin moment $S$, the theoretical entropy change is given by $\Delta S_{\text {mag }}=R \ln (2 S+1)$. For $S=1 / 2$ value of $\Delta S_{\text {mag }}=5.76 \mathrm{~J} \mathrm{~mol}^{-1} \mathrm{~K}^{-1}$ results, which is larger than our experimental finding. On the other hand, due to the rather extended temperature range that had to be excluded from the fit, we cannot completely rule out the possibility of slightly larger values. Nevertheless, the obtained values are far from the expected ones, considered that $\Delta S_{\text {mag }}$ was calculated with respect to one formula unit (not per Co atom). Our specific heat measurements may be explained assuming that only the spin of one electron of one $\mathrm{Co}^{2+}$ per formula unit participates in the magnetic ordering. This interpretation agrees with the rather low saturation magnetization (Fig. 6, middle). At $50 \mathrm{~K}$ (i.e. in the region between $T_{\mathrm{N}}$ and $T_{1}$ ) the $M_{\mathrm{S}}$ accounts to $\approx 0.33$ $\mu_{\mathrm{B}} /$ Co, respectively $\approx 1 \mu_{\mathrm{B}} /$ f.u. According to $M_{\mathrm{S}} / \mu_{\mathrm{B}}=2 \times S$ this value reflects a spin of $S=1 / 2$ (Please note that this value corresponds to the ordered spin moment only and not to the total). While this value might be somewhat too small as the temperature is close to $T_{\mathrm{N}}$, the general statement that the ordered magnetic moment is much smaller than the total one remains valid. Additional neutron diffraction experiments may be helpful to further examine the temperature dependence of the magnetic ordering in $\mathrm{HP}-\mathrm{Co}_{3} \mathrm{TeO}_{6}$.

Magnetoelectric properties. The field-dependent magnetoelectric signal was measured between 65 and $10 \mathrm{~K}$. As visible in Fig. 8, no significant ME-response was found for temperatures down to $60 \mathrm{~K}$, while at $55 \mathrm{~K}$ a negative peak appears at approximately $+4.5 \mathrm{kOe}$ and symmetrically a positive peak at the corresponding negative field. With decreasing temperature, the peaks shift to higher fields and their intensities reach a maximum at $45 \mathrm{~K}$. In addition, the peaks become broader and vanish below $25 \mathrm{~K}$. These temperatures correlate with the Néel temperature $\left(T_{\mathrm{N}}=58.2 \mathrm{~K}\right)$ and with $T_{1}(21 \mathrm{~K})$ determined from magnetic- and specific heat measurements described above.

For a quantitative analysis the peaks were fitted using the asymmetric function given in eqn (4).

$$
\begin{aligned}
\alpha_{\mathrm{ME}}= & \alpha_{\mathrm{ME}, 0}+\frac{\alpha_{\mathrm{ME}, \max }}{1+\mathrm{e}^{-\left(\frac{H-H_{\max }+\mathrm{FWHM} / 2}{w_{1}}\right)}} \\
& \times\left(1-\frac{1}{1+\mathrm{e}^{-\left(\frac{H-H_{\max }-\mathrm{FWHM} / 2}{w_{2}}\right)}}\right)
\end{aligned}
$$

Here, $\alpha_{\mathrm{ME}, 0}$ is the offset, and $w_{1}$ and $w_{2}$ are the shape parameters.

The obtained characteristic values, i.e. the position of the peak maximum/minimum $\left(H_{\max }\right)$, its full width at half maximum (FWHM) and values at the maximum/minimum of the peaks $\left(\alpha_{M E, m a x}\right)$ are shown in Fig. 9. It turned out that the two peaks at positive and negative magnetic fields are centro symmetric with respect to $H=0$. Therefore, averaged values are depicted. In the temperature regime $T_{\mathrm{N}} \leq T \leq T_{1} \alpha_{\mathrm{ME} \text {,max }}$ increases with decreasing temperature from 6.4 to $12.7 \mu \mathrm{V} \mathrm{Oe}^{-1} \mathrm{~cm}^{-1}$ at $45 \mathrm{~K}$ and re-decreases to $2.1 \mu \mathrm{V} \mathrm{Oe}^{-1} \mathrm{~cm}^{-1}$ at $25 \mathrm{~K}$. In contrast, both the magnetic field of the peak maximum and its FWHM increase continuously with decreasing temperature. For all three values, the change between 55 and $50 \mathrm{~K}$ is strongest.

In the ME investigations described so far, the voltage was measured parallel to the applied magnetic field. Fig. SI5 (ESI $\dagger$ ) shows additional measurements, in which the ME voltage generated perpendicular to the magnetic field was recorded by positioning the disk-shaped samples upright. The general trend is similar to the parallel orientation but there are also distinct differences: The sign of $\alpha_{\mathrm{ME}}$ is inverted, i.e., a positive peak occurs at positive fields and the magnitudes of the peaks are clearly smaller. At $20 \mathrm{~K}$ the ME signal has not completely

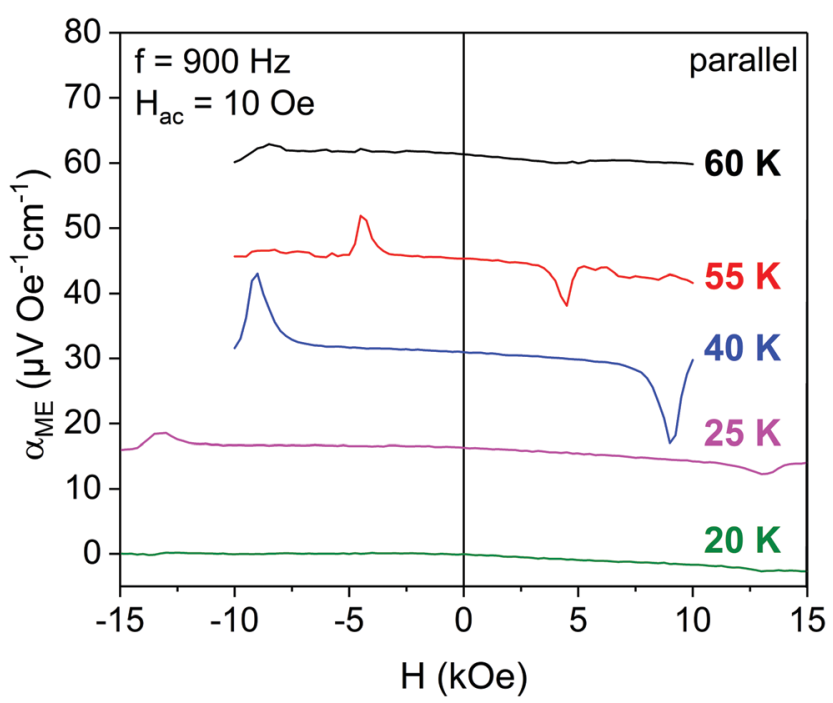

Fig. 8 Field dependence of the parallel magnetoelectric coefficient measured at different temperatures. Values recorded above $20 \mathrm{~K}$ are depicted with an offset. 


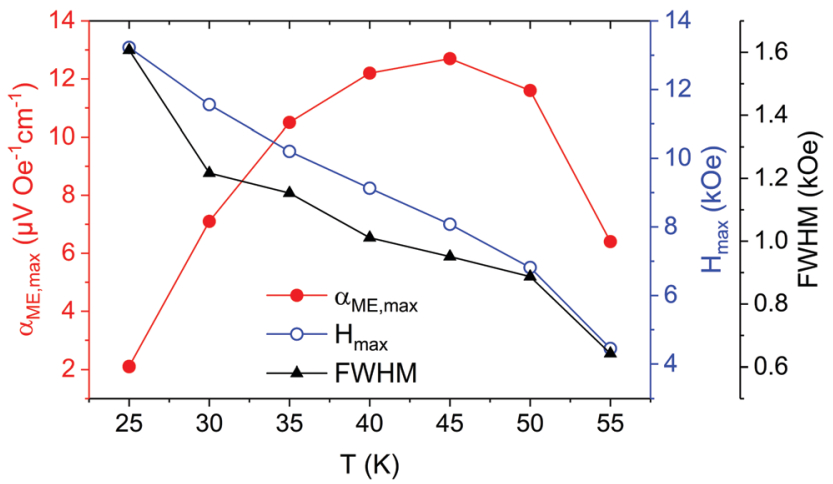

Fig. 9 Amplitude, field position and full width at half maximum of the $\alpha_{M E}$ peak measured in parallel geometry.

vanished but a step-like feature remains. Fig. SI6 (ESI $\dagger$ ) shows the results of the peak fitting for the perpendicular orientation. The magnetic field at which the ME-peaks occur $\left(H_{\max }\right)$ are very similar compared to the parallel orientation and $\alpha_{\mathrm{ME} \text {,max }}$ has its highest value at $45 \mathrm{~K}$, too. On the other hand, the absolute values of $\alpha_{\mathrm{ME} \text {,max }}$ are about $40 \%$ smaller for the perpendicular orientation and the FWHM values are reduced. Due to the small signals the values of $\alpha_{\mathrm{ME} \text {,max }}$ and in particular of the FWHM possess a larger uncertainty and therefore for the latter no clear trend can be determined.

The reversed sign and smaller magnitude of $\alpha_{\mathrm{ME}}$ in perpendicular orientation of $\mathrm{H}$ and $\mathrm{P}$ can be explained assuming that the magnetoelectric coupling in $\mathrm{HP}-\mathrm{Co}_{3} \mathrm{TeO}_{6}$ is mediated by mechanical deformation, i.e., magnetostriction. If the cell volume remains constant, an elongation in direction of the magnetic field results in a shortening perpendicular to it (respectively vice versa). For small magnetostriction (typically in the order $10^{-5}$ ) the value of the transverse deformation is about half of the one in field direction. In turn, the perpendicular ME voltage is expected to be roughly $-1 / 2$ of the parallel one in good agreement with experiment. It is to be noted that we have observed this relation between $\alpha_{\mathrm{ME} \|}$ and $\alpha_{\mathrm{ME} \perp}$ in composite multiferroics like $\mathrm{CoFe}_{2} \mathrm{O}_{4} / \mathrm{BaTiO}_{3}$ or $\mathrm{Ni} / \mathrm{BaTiO}_{3}$, too. ${ }^{65,66}$

At selected temperatures the ME voltage was measured with different field sweep directions. No significant deviations were found between the data recorded at increasing and decreasing field, respectively, proving a non-hysteretic behavior of the magnetoelectric coupling. In addition, measurements at different frequencies of the ac-magnetic field were carried out at $45 \mathrm{~K}$ for both orientations. As shown in Fig. 10, a significant increase by a factor of roughly 2.5 in the range 100 to $900 \mathrm{~Hz}$ was observed for both parallel and perpendicular orientation. The reasons for this increase as well as for the loss of the ME effect below $20 \mathrm{~K}$ need to be established in further experiments.

For the parallel orientation a second set of measurements was carried out after applying an electric field of $800 \mathrm{~V}$ to the sample for 24 hours at room temperature. Such an electrical poling was found to be essential for the detection of an $\mathrm{ME}$ signal in type-I magnetoelectric composites, e.g. $\mathrm{BaTiO}_{3} /$ $\mathrm{CoFe}_{2} \mathrm{O}_{4}{ }^{67}$ or $\mathrm{BaTiO}_{3} / \mathrm{CoFe}_{2}{ }^{68}$ In the case of $\mathrm{HP}^{6}-\mathrm{Co}_{3} \mathrm{TeO}_{6}$ the results were almost identical with the ones without poling.

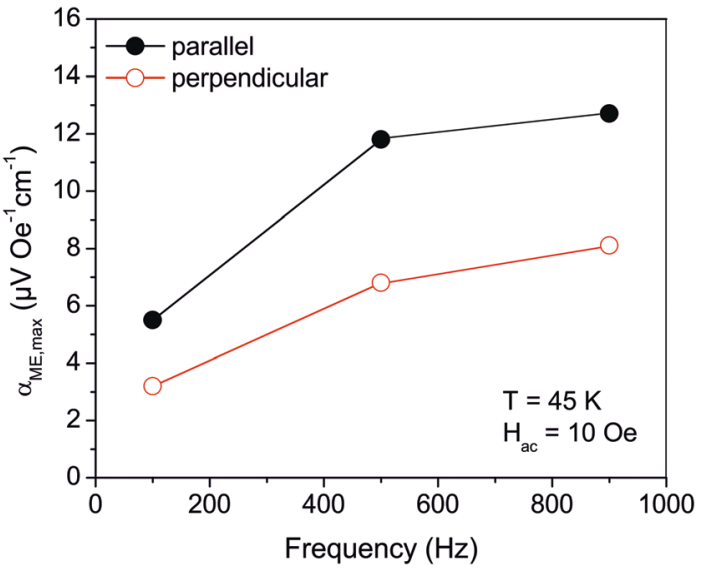

Fig. 10 Amplitude of the magnetoelectric signal measured with different frequencies of the $H_{\mathrm{ac}}$-driving field.

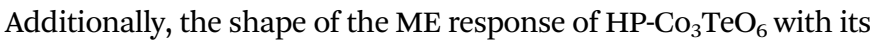
well-defined rather sharp peaks is completely different from the ones of magnetoelectric composites, e.g. the above-mentioned $\mathrm{BTO} / \mathrm{CFO}$ system. Finally, we emphasize that in $\mathrm{HP}^{-} \mathrm{Co}_{3} \mathrm{TeO}_{6}$ the ME voltage was not detected for $T>T_{\mathrm{N}}$, thus it is coupled to the occurrence of the magnetic ordering. These findings clearly indicate that $\mathrm{HP}-\mathrm{Co}_{3} \mathrm{TeO}_{6}$ is type-II magnetoelectric.

\section{Conclusions}

Under high-pressure/high-temperature conditions of $6.5 \mathrm{GPa}$ and $1073 \mathrm{~K}, \mathrm{Co}_{3} \mathrm{TeO}_{6}$ transforms from a monoclinic lithium cryolitetype structure $(C 2 / c)$ to the acentric $\mathrm{Ni}_{3} \mathrm{TeO}_{6}$-type structure $(R 3)$. The high-pressure modification of $\mathrm{Co}_{3} \mathrm{TeO}_{6}$ is stable up to a maximum temperature of $1070 \mathrm{~K}$ at ambient conditions and was characterized by powder and single-crystal X-ray diffraction. Comparable to $\mathrm{Ni}_{3} \mathrm{TeO}_{6}$ an antiferromagnetic ordering below $T_{\mathrm{N}}=58.2(1) \mathrm{K}$ as well as a spin-flop-type transition at $T=3 \mathrm{~K}$ and a critical magnetic field of $H_{\text {crit }}=10.8(1) \mathrm{kOe}$, was observed. Both compounds, $\mathrm{Ni}_{3} \mathrm{TeO}_{6}$ $\left(T_{\mathrm{N}}=52 \mathrm{~K}^{9}\right)$ and $\mathrm{Co}_{3} \mathrm{TeO}_{6}$, show a strong correlation between crystal structure and Néel-Temperature. Furthermore, there is a clear dependence of the occurrence of ME effects on the presence of a magnetic order, proving that $\mathrm{HP}^{-\mathrm{Co}_{3}} \mathrm{TeO}_{6}$ is a type-II magnetoelectric material. In the temperature regime between $T_{\mathrm{N}}$ and $T_{1}=$ $21 \mathrm{~K}$ considerable ME voltages were detected and no significant deviations between increasing and decreasing field proved a nonhysteretic behavior of the magnetoelectric coupling. The magnetic entropy changes at the two transitions $\left(T_{\mathrm{N}}, T_{1}\right)$ as well as the low saturation magnetization can be explained assuming that the spin of only one electron of one $\mathrm{Co}^{2+}$ per formula unit is involved in the magnetic order. This has to be verified by neutron diffraction experiments in future.

\section{Author contributions}

E. Selb: investigation, visualization, writing - original draft; T. Buttlar: investigation, visualization; O. Janka: investigation, visualization, supervision, writing - review \& editing; M. Tribus: 
investigation; S. G. Ebbinghaus: data analysis, supervision, writing - review \& editing and G. Heymann: data analysis, conceptualization, supervision, writing - review \& editing.

\section{Conflicts of interest}

There are no conflicts to declare.

\section{Acknowledgements}

We would like to thank Prof. Dr H. Huppertz for continuous support and usage of all the facilities of the Institute of General, Inorganic and Theoretical Chemistry, University of Innsbruck. Furthermore, we thank T. Miller and Prof. Dr W. Schnick (LMU Munich) for recording the temperature-dependent X-ray diffraction data.

\section{Notes and references}

1 W. Eerenstein, N. D. Mathur and J. F. Scott, Nature, 2006, 442, 759-765.

2 M. Fiebig, T. Lottermoser, D. Meier and M. Trassin, Nat. Rev. Mater., 2016, 1, 16046.

3 N. A. Spaldin and M. Fiebig, Science, 2005, 309, 391-392.

4 R. Mathieu, S. A. Ivanov, P. Nordblad and M. Weil, Eur. Phys. J. $B, 2013,86,361$.

5 D. Khomskii, Physics, 2009, 2, 20.

6 S.-W. Cheong and M. Mostovoy, Nat. Mater., 2007, 6, 13.

7 R. E. Newnham and E. P. Meagher, Mater. Res. Bull., 1967, 2, 549-554.

8 L. Zhao, C. H. Du and A. C. Komarek, Phys. Status Solidi RRL, 2017, 11, 1700073.

9 J. W. Kim, S. Artyukhin, E. D. Mun, M. Jaime, N. Harrison, A. Hansen, J. J. Yang, Y. S. Oh, D. Vanderbilt, V. S. Zapf and S. W. Cheong, Phys. Rev. Lett., 2015, 115, 137201.

10 I. Živković, K. Prša, O. Zaharko and H. Berger, J. Phys.: Condens. Matter, 2010, 22, 056002.

11 Y. S. Oh, S. Artyukhin, J. J. Yang, V. Zapf, J. W. Kim, D. Vanderbilt and S.-W. Cheong, Nat. Commun., 2014, 5, 3201.

12 A. Hostachy and J. Coing-Boyat, C. R. Seances Acad. Sci., Ser. B, 1968, 267, 1435-1438.

13 K. Y. Choi, P. Lemmens, E. S. Choi and H. Berger, J. Phys.: Condens. Matter, 2008, 20, 505214.

14 M. Weil, Acta Crystallogr., Sect. E: Struct. Rep. Online, 2006, 62, i244-i245.

15 L. I. Kosse, E. D. Politova, V. V. Chechkin, E. A. Myzgin, B. S. Medvedev and Y. N. Venevtsev, Inorg. Mater., 1982, 18, 1616-1619.

16 S. A. Ivanov, P. Nordblad, R. Mathieu, R. Tellgren, C. Ritter, N. V. Golubko, E. D. Politova and M. Weil, Mater. Res. Bull., 2011, 46, 1870-1877.

17 Á. M. Arévalo-López, E. Solana-Madruga, C. AguilarMaldonado, C. Ritter, O. Mentré and J. P. Attfield, Chem. Commun., 2019, 55, 14470-14473.
18 R. Becker, M. Johnsson and H. Berger, Acta Crystallogr., Sect. C: Cryst. Struct. Commun., 2006, 62, i67-i69.

19 M. Hudl, R. Mathieu, S. A. Ivanov, M. Weil, V. Carolus, T. Lottermoser, M. Fiebig, Y. Tokunaga, Y. Taguchi, Y. Tokura and P. Nordblad, Phys. Rev. B: Condens. Matter Mater. Phys., 2011, 84, 180404.

20 S. A. Ivanov, R. Tellgren, C. Ritter, P. Nordblad, R. Mathieu, G. André, N. V. Golubko, E. D. Politova and M. Weil, Mater. Res. Bull., 2012, 47, 63-72.

21 D. Reichartzeder, M. Wildner, M. Weil, S. Ivanov, A. Stash and Y.-S. Chen, Eur. J. Inorg. Chem., 2018, 4221-4233.

22 C.-H. Lee, C.-W. Wang, Y. Zhao, W.-H. Li, J. W. Lynn, A. B. Harris, K. Rule, H.-D. Yang and H. Berger, Sci. Rep., 2017, 7, 6437.

23 H. Singh, H. Ghosh, T. V. C. Rao, G. Sharma, J. Saha and S. Patnaik, J. Appl. Phys., 2016, 119, 044104.

24 C.-W. Wang, C.-H. Lee, C.-Y. Li, C.-M. Wu, W.-H. Li, C.C. Chou, H.-D. Yang, J. W. Lynn, Q. Huang, A. B. Harris and H. Berger, Phys. Rev. B: Condens. Matter Mater. Phys., 2013, 88, 184427.

25 J. Isasi, J. Alloys Compd., 2001, 322, 89-96.

26 N. V. Golubko, V. Y. Proidakova, G. M. Kaleva, S. A. Ivanov, A. V. Mosunov, S. Y. Stefanovich, N. V. Sadovskaya, E. D. Politova and P. Nordblad, Bull. Russ. Acad. Sci., Phys., 2010, 74, 724-726.

27 H. Huppertz, G. Heymann, U. Schwarz and M. R. Schwarz, in Handbook of Solid State Chemistry, ed. R. Dronskowski, S. Kikkawa and A. Stein, Wiley-VCH, Weinheim, 2017, vol. 2, ch. 2, pp. 23-48.

28 H. Huppertz, Z. Kristallogr., 2004, 219, 330-338.

29 P. Thompson, D. E. Cox and J. B. Hastings, J. Appl. Crystallogr., 1987, 20, 79-83.

30 R. A. Young and P. Desai, Arch. Nauki Mater., 1989, 10, 71-90.

31 M. C. Morris, H. F. McMurdie, E. H. Evans, B. Paretzkin, H. S. Parker and N. P. Pyrros, Natl. Bur. Stand., 1984, 25, 62. 32 APEX3 (v. 2017.3-0), CELL_NOW (v. 2008/4), SAINT (v. 8.38A), TWINABS (v. 2012/1), and SADABS (v. 2016/2), Bruker AXS GmbH, Karlsruhe (Germany).

33 OPUS (v 7.2), Bruker AXS GmbH, Billerica, USA, 2012.

34 J. Tauc, Mater. Res. Bull., 1970, 5, 721-729.

35 P. Kubelka and F. Munk, Z. Tech. Phys., 1931, 12, 593-601. 36 T. Walther, U. Straube, R. Köferstein and S. G. Ebbinghaus, J. Mater. Chem. C, 2016, 4, 4792-4799.

37 OriginPro, OriginLab Corporation, Northampton, USA, 2018G SR1 edn., 2017.

38 G. Sheldrick, Acta Crystallogr., Sect. A: Found. Adv., 2015, 71, 3-8.

39 G. Sheldrick, Acta Crystallogr., Sect. C: Struct. Chem., 2015, 71, 3-8.

40 G. M. Sheldrick, ShelXL - Crystal Structure Refinement Multi-CPU Version, University of Göttingen, Göttingen (Germany), 2017/1 edn., 2017.

41 Y. Le Page, J. Appl. Crystallogr., 1988, 21, 983-984.

42 A. Spek, Acta Crystallogr., Sect. D: Biol. Crystallogr., 2009, 65, 148-155. 
43 R. Becker and H. Berger, Acta Crystallogr., Sect. E: Struct. Rep. Online, 2006, 62, i222-i223.

44 C. T. Prewitt and R. T. Downs, Rev. Mineral. Geochem., 1998, 37, 283-317.

45 H. Schulz and G. Bayer, Acta Crystallogr., Sect. B: Struct. Crystallogr. Cryst. Chem., 1971, 27, 815-821.

46 I. D. Brown, The Chemical Bond in Inorganic Chemistry: The Bond Valence Model, Oxford University Press, New York, 2016.

47 N. E. Brese and M. O'Keeffe, Acta Crystallogr., Sect. B: Struct. Sci., 1991, 47, 192-197.

48 I. D. Brown and D. Altermatt, Acta Crystallogr., Sect. B: Struct. Sci., 1985, 41, 244-247.

49 R. Hoppe, S. Voigt, H. Glaum, J. Kissel, H. P. Müller and K. Bernet, J. Less-Common Met., 1989, 156, 105-122.

50 R. Hoppe, Angew. Chem., Int. Ed. Engl., 1970, 9, 25-34.

51 R. Hoppe, Angew. Chem., Int. Ed. Engl., 1966, 5, 95-106.

52 S. Sasaki, K. Fujino, T. Eacute and Y. Uchi, Proc. Jpn. Acad., Ser. B, 1979, 55, 43-48.

53 M. Dušek and J. Loub, Powder Diffr., 1988, 3, 175-176.

54 K. Kohn, K. Inoue, O. Horie and S.-I. Akimoto, J. Solid State Chem., 1976, 18, 27-37.

55 E. Selb, L. Declara, L. Bayarjargal, M. Podewitz, M. Tribus and G. Heymann, Eur. J. Inorg. Chem., 2019, 4668-4676.

56 G. Blasse and W. Hordijk, J. Solid State Chem., 1972, 5, 395-397.
57 C.-W. Tang, C.-B. Wang and S.-H. Chien, Thermochim. Acta, 2008, 473, 68-73.

58 P. Yasodha, M. Premila, A. Bharathi, M. C. Valsakumar, R. Rajaraman and C. S. Sundar, J. Solid State Chem., 2010, 183, 2602-2608.

59 G. A. Bain and J. F. Berry, J. Chem. Educ., 2008, 85, 532.

60 S. G. Ebbinghaus, E.-W. Scheidt and T. Götzfried, Phys. Rev. B: Condens. Matter Mater. Phys., 2007, 75, 144414.

61 S. Riegg, A. Günther, H. A. Krug von Nidda, A. Loidl, M. V. Eremin, A. Reller and S. G. Ebbinghaus, Phys. Rev. B: Condens. Matter Mater. Phys., 2012, 86, 115125.

62 S. Riegg, A. Günther, H. A. Krug von Nidda, M. V. Eremin, A. Reller, A. Loidl and S. G. Ebbinghaus, Eur. Phys. J. B, 2012, 85, 413.

63 J. L. Her, C. C. Chou, Y. H. Matsuda, K. Kindo, H. Berger, K. F. Tseng, C. W. Wang, W. H. Li and H. D. Yang, Phys. Rev. B: Condens. Matter Mater. Phys., 2011, 84, 235123.

64 R. Mathieu, S. A. Ivanov, P. Nordblad and M. Weil, Eur. Phys. J. B, 2013, 86, 361.

65 M. Breitenbach, H. Deniz and S. G. Ebbinghaus, J. Phys. Chem. Solids, 2019, 135, 109076.

66 T. Buttlar, T. Walther, K. Dörr and S. G. Ebbinghaus, Phys. Status Solidi B, 2020, 257, 1900622.

67 M. Breitenbach and S. G. Ebbinghaus, J. Cryst. Growth, 2018, 483, 81-88.

68 T. Walther, R. Köferstein and S. G. Ebbinghaus, J. Am. Ceram. Soc., 2017, 100, 1502-1507. 